\title{
On Farmers Markets as Wicked Opportunities
}

\author{
Alfonso Morales (iD \\ Department of Planning and Landscape Architecture, College of Letters and Science, \\ University of Wisconsin-Madison, Madison, WI 53706, USA; morales1@wisc.edu
}

check for updates

Citation: Morales, A. On Farmers Markets as Wicked Opportunities. Sustainability 2021, 13, 6108. https:// doi.org/10.3390/su13116108

Academic Editor: Michael S. Carolan

Received: 17 April 2021

Accepted: 24 May 2021

Published: 28 May 2021

Publisher's Note: MDPI stays neutral with regard to jurisdictional claims in published maps and institutional affiliations.

Copyright: (C) 2021 by the author. Licensee MDPI, Basel, Switzerland. This article is an open access article distributed under the terms and conditions of the Creative Commons Attribution (CC BY) license (https:/ / creativecommons.org/licenses/by/ $4.0 /)$.

\begin{abstract}
Marketplaces are almost as old as humanity. They result from trade and trade is structured by political, religious, social, and economic needs. Overtime, marketplaces have woven together relational processes representing each of these, in order to host trade, social life, political life, and all manner of economic activities. So, markets are bundles of activities tightly related reciprocally with, and in the context of social institutions. Likewise, marketplaces manifest expectations for how society sees itself and for how societies govern themselves. It is this framing opportunity which I exploit here. In this article I pursue the reconstruction of wicked problems to show how marketplaces are wicked opportunities. Wicked opportunity thinking can be applied to many other aspects of our contemporary life.
\end{abstract}

Keywords: wicked problems; marketplaces; food systems; social theory; food distribution; food security; ecosystems services; regulation; farm to institution

\section{Introduction}

COVID-19 initially disrupted the labor force, and healthcare and caused breakages in long supply chains. Grocery store shelves emptied, whereas farmers markets often did robust business, supplying consumers with locally produced food. COVID-19 sharpened our focus and produced clear goals oriented around some shared values. Yet our food supply presented wicked problems where values were contested and problems in the supply chain were ill-defined and complex, and uncertainty was rampant. When these supply chains were broken, we were unsure when activities and processes would again become predictable. Knowing another pandemic or similar problem will happen again, the question now is, will we see the same difficulties in the future, and why?

My answer is yes. Pandemics fall under the category of wicked problems: troubles which are difficult to define and measure, unclear in cause and effect, and without a clear ending point. These are problems without a technical solution, and the difficulties formulating technical solutions are compounded by inflexible, disinterested, or myopic social, economic, and political organizations. The same is true for our planet's "silent killer," climate change. For instance, commodity food production evolved from technical solutions to tractable problems; in turn it connected to other efficiencies in processing and distribution, but in turn these production processes are destroying our ecology, marginalizing economic actors, and alienating people from food. In other words, commodity food production became a wicked problem, connecting to and producing other problems.

Wicked problems compound complex technical problems with organizational expectations and practices operating at the size and scale of mid-20th century industrial bureaucracy. Wicked problems resist disaggregation into component threads, with each having its formulaic solutions. Instead, to make progress with wicked problems, we must combat them with what I call "wicked opportunities," which are similar in that they are also difficult to define and measure, unclear in cause and effect, and thankfully can go on and on. One wicked opportunity is the farmers market and similar multi-functional outdoor activities and marketplaces. 
Farmers markets are wicked opportunities because they weave together many activities and processes, producing social integration (even if by conflict), ecological awareness and caring, and economic inclusivity. Throughout the ages, and until a century ago, public markets were recognized and established by governments to ameliorate shocks in urban systems from inadequate food access, unemployment, and immigration [1]. More recently, the many benefits of markets have been characterized, and research has described the utility of markets for community development [2,3]. Pre-COVID, marketplaces had been left to their own devices. During COVID, markets have proven themselves to be wicked opportunities, adaptive to a variety of threats. We need to understand how marketplaces are resources in their practices of responding to myriad threats, from climate change to COVIDs.

In this essay I elaborate this thesis: marketplaces oriented to local and regional agriculture and other production realize opportunities that are difficult to define and measure, unclear in cause and effect, and with no foreseeable ending point. I will demonstrate this by reviewing briefly the nature of wicked problems and how they manifest in climate change and the food system, and to each of those, how marketplaces provide an equally "wicked" response.

\section{On the Wicked Problem}

In the mid-20th century, despite Weber's warnings on the nature of bureaucracy [4,5], industrial societies were flush with hope for technical solutions to contemporary problems. They believed these solutions were appropriate, given how they had successfully dealt with the massive technical problems of wartime production, mass education, and improved infrastructure. Into this relative optimism stepped Rittel and Webber [6], focused as they were on diagnosing problems associated with rational and comprehensive planning processes. Rittel and Webber contended that these processes could solve "tame" problems and discern the contours of emergent difficulties, but are incapable of clarifying and resolving those difficulties.

Rittel and Webber described professionalism as the vehicle for applying science to the various opportunities and problems emerging in modern society. For them, public sector planning was among the professions imbued by society with expectations for making societal improvements, but often without clearly defined goals and in the presence of diverse and conflicting values. Professions, including urban planning, which were developing to address problems were "dominated by the pervasive idea of efficiency" [6] (p. 158, their emphasis). Rittel and Webber described how efficiency, while claimed by early professionals and applicable to the "tame" problems often found in technical fields, soon ran up against the difficulty of defining problems, much less solving them. Essentially, these professionals described "how an idealized planning system would function" [6] (p. 159), without a consensus on whether such a system was desirable, much less workable.

From this assessment, Rittel and Webber describe how social problems are either tame or wicked. The tame problem is one that can be formulated; that is to say, clarified and known, and thus addressed by way of technical solutions. They opposed the tame to the wicked, which from the outset is a problem without an adequate formulation, much less a solution. They recognized wicked problems as those without technical solutions and, further, without clear goals, and in socio-organizational and even societal circumstances, without shared values. One analog was the practice of scenario planning, of which they were aware [6] (p. 169), but their focus was on the nature of public sector planning, where besides the absence of shared values, problems are often undefined, complex, and uncertain. These problems are part of unpredictable processes, which constantly generate new and similarly difficult situations, where every intervention is consequential, because "every trial counts" [6] (p. 163, their emphasis). Despite these difficulties, these problems are high-stakes ones, and we must work towards their solution.

Tools to support professionals in their work with wicked problems have emerged over the years. For me, scenario planning is one such tool that can foster dialogue and 
discernment by orienting participants to possible futures [7,8]. However, for Rittel and Webber, "There seems to be a growing realization that a weak strut in the professional's support system lies at the juncture where goal-formulation, problem-definition and equity issues meet" [6] (p. 156), and further, "We are inclined to think that these theoretic dilemmas may be the most wicked conditions that confront us" [6] (p. 169). It is to questions of theory we now turn; not "theory" in the grand sense dominant in the mid-20th century, but instead theory of the practical beliefs orienting interaction in local communities. Beginning with a brief and incomplete description and illustration of the wicked opportunity, I will show how people transform wicked problems into wicked opportunities.

\section{On the Wicked Opportunity}

In our contemporary scene, social, economic, and environmental problems are pressing. Likewise, political will is evaporating with the heating planet. About 50 years ago, Rittel and Weber wrote of the wicked problem, a class of problems beyond device and resolve that challenge us and compel us to innovate. These innovations share some common features: interaction from multiple perspectives, a narrative orientation, flexible organization, and generative regulatory frameworks [6]. I began using the term "wicked opportunities" for these activities that help reconstruct problematic socio-organizational circumstances and contexts [6], and in 2014 I developed the idea for the lecture, "Wicked Problems? Wicked Opportunities! Direct and Indirect Responses to Climate Change and Ensuing Natural Hazards" to the UW-Madison program, Climate, People, and Environment. Subsequently, the idea has found a home in business consulting, as wicked opportunity, or wicked solutions.

Rittel and Webber described mid-20th century America as a nation of conflict between people with an almost mystical view of the future versus those with a more mechanistic view [7] (p. 158), and such dichotomies are frequently deployed in Hegelian descriptions of society. I believe that such framing is empty of use, with the exception of as an occasional illustration. Rittel and Webber's formulation of the wicked problem followed from how they located it politically and professionally in what was called "mass society." My formulation of the wicked opportunity uses a different starting point. The wicked opportunity begins with what people are doing in their specific circumstances, with the tools they have available, conceptual and technical, oriented as they are to their particular goals and purposes, but open as they can sometimes be to emergent connections with other goals and purposes. People in their circumstances might consider the regional, national, or global view, and their concrete activities might evoke the law or regulations of governments, but many local activities reflect state or national law and in turn are adopted by other localities. I am not ignoring the larger scale but comprehending its influences in local interactions. As the bumper sticker suggests, "think globally, act locally".

For complex, ill-defined problems, our starting point will be in the distributed approaches people are undertaking in their local context. Farmers markets epitomize locally organized activities that represent locally and regionally produced goods. For generations, marketplaces have contributed to communities in many ways [8-11]. This literature has shown that market managers and marketplaces:

1. Promote individual and public health;

2. Serve as conduits for information and healthy food;

3. Offer opportunities for ecological education, physical exercise, and social life;

4. Provide learning opportunities for immigrants and other sectors of a community.

For these reasons, farmers markets are often hubs of vibrant communities. Each market purpose articulates constellations of perspectives and problems marketplaces resolve into opportunities. For instance, for various reasons the industrial food system excludes many people from opportunities to consume healthy food [6]. The problems grocery stores have with supply chains, labor, insurance, and other constraints of contemporary neoliberal economy $[6,12]$ are addressed in farmers markets through local sourcing, short supply chains, and self-contained labor forces that do not have the same infrastructural needs as 
grocery stores. For instance, when COVID-19 initially caused breakages in long supply chains, grocery store shelves emptied, whereas farmers markets often did robust business supplying consumers with locally produced food.

Needless to say, food is a high-stakes problem. Retail grocery chains represent the end of efficient but brittle supply chains, which operate successfully if undisturbed. Unfortunately, disturbances were always present, and are multiplied in our current circumstances. Intersecting problems associated with climate change, decaying infrastructure, and other hazards emerging from the natural environment, such as COVID-19, easily break these long supply chains. Possible vulnerabilities at each stage of the supply chain can bring supply to a halt. During production, practices are subject to hydroponic and soil microbial problems; proceeding into food processing and distribution, insufficient supply or sick labor forces can also bottleneck the availability of food.

The COVID-19 pandemic sharpened our focus and produced clear goals oriented around some basic shared values. Yet our food supply chains still present wicked problems where values are frequently contested, problems within the chain are ill-defined, and complexity and uncertainty are rampant. When these supply chains are broken, we are unsure of when activities and processes will again become predictable.

Farmers market managers and other direct market food sellers responded rapidly to the circumstances of COVID-19, accommodating the shift in demand from grocery stores to outdoor markets and pick-up or delivery of food. These managers experimented with new ideas in their unpredictable settings, and they understood well that regardless of whether they succeeded or failed, their trials had stakes.

\subsection{Wicked Opportunities: A Brief Excursus on Farmers Markets and COVID-19}

In today's world, farmers and other outdoor markets are considered essential services around the U.S. and elsewhere [13], in farmers markets [14], and in marketplaces generally [6], and managers are responding to community needs in many ways. To exploit the new niches produced in the economic ecology by the COVID crisis, markets have created "drive-through" markets and online marketplaces to help produce economic and food security. True, these responses may continue in usefulness in the years ahead, not simply as functional alternatives in times of crisis, but also to increase access among some populations. That said, these practices at best only partially fulfill the educational, social, and political reasons people visit markets. These organizational models and technological tools are stop-gaps and cannot replace other facets of the familiar images of marketplaces in the media or our memories.

While alternative sales practices will likely linger post-COVID, waiting in line at familiar places leaves people wanting the market interactions they miss. Market managers recognize that their markets are more than economic opportunities, and they problem-solve to retain some level of in-person interaction amid this ongoing pandemic Managers either experiment with their physical spaces, such as painting lines on the ground, or using traffic cones and the like, or they experiment with the timing of the market, dividing the market day into time periods and permitting a specific number of people to shop in each. Markets also provide personal protective equipment of various kinds to increase the safety of visitor and vendor interactions. Of course, markets also wait patiently for principles to follow in designing responses to their rapidly changing circumstances. They wait for the government to act on the wicked opportunities represented by marketplaces, and to support practices that are responsive to circumstances, experimental, better than alternatives, that overlap with solutions to other problems, and of immediate local importance. Local and state governments should harness the creativity displayed by marketplaces. However, governments are often impeded by the siloed nature of their interactions [15].

Meanwhile, markets operate by way of principles we can characterize as wicked opportunities:

1. They can be defined by context and they connect locally produced crafts and foods with consumers;

2. They are ongoing experiments in practicing community; 
3. They convey information and opportunities people will discover and reinterpret to solve other problems.

These principles are realized in creative market management practices and permit managers to pivot swiftly in response to emergency situations. Market managers do not have to rethink their business models and organizational practices, nor rebuild complex supply chains. Indeed, they remain ready to engage the government in formulating realistic expectations for marketplaces. In turn, they can communicate expectations to vendors and visitors who will help produce a market that minimizes risk and provides local products, practices community building, and provides opportunities for learning. Let me turn to applying these principles in terms of agriculture and ecosystem services.

\subsection{Wicked Opportunities: A Brief Excursus on Farmers Markets and Ecosystem Services}

We know that the practice of conventional or industrial agricultural practices eliminates the chance of achieving global climate change objectives [16]. But, agriculture has the potential to help achieve those objectives by mitigating greenhouse gas emissions through carbon sequestration [17]. Regenerative (ill-defined as it is) agriculture has emerged as one effective solution to storing carbon in the soil; it includes practices such as diversifying the kinds of crops planted, integrating crops with livestock systems, using cover crops, and planting forage and perennial crops, among others. This approach to farming not only supports climate change mitigation but commits more broadly to ecological and social goals. A wicked opportunity exists in the ability of regenerative practices to maximize ecosystem services of healthy soil, water, air, food, communities, and biodiversity, while tackling climate change.

Farmers, large and small, are acting on their values and those of consumers by adopting practices to mitigate climate change and capture the benefits of ecosystem services. Though direct market farmers are profit-seekers, they are willing to experiment with their production practices to respond to community concerns and interests. This responsiveness is especially encouraged by regular face-to-face interaction with consumers at farmers markets. Producers cite ecological benefits as a major factor in their choice to sell directly to consumers [18]. Additionally, the health of the environment, humans, and animals seem connected as motivations for farmers' practices. Prompted by farmers in Nova Scotia and Wisconsin, we at Farm 2 Facts in the University of Wisconsin-Madison have developed a metric that models various ecosystem services to show how the practices of small, direct market farmers are contributing to climate change objectives. Moreover, we will be modeling how they are contributing to broader ecological objectives by revealing farmers' attention to their local ecological processes and their support of biodiversity.

Farmers markets are sensitive to changes in their environment due to their flexibility and porous organization - at the market, many conditions may pass through. Any given market day or season may have a clear ending point or beginning point, but those details change in response to conditions, and the market as an organization is a relatively open system. As an extension of local food systems, farmers markets have an opportunity to convey their positive benefits to a variety of ecosystem services. Farmers markets and producers who engage the community can tell the story of food in relation to land and communicate ecosystem benefits from regenerative and similar production practices.

Markets demonstrate that to describe a wicked opportunity in detail is not only difficult, but unimportant, because the problems markets can address are emergent. Instead of a need for detailed description, the wicked opportunity reminds us to pay attention to the ongoing and how its practice or reconstruction relates to the aspirational and possible. This is in contrast to that of the wicked problem, of which Rittel and Webber write: "in order to describe a wicked-problem in sufficient detail, one has to develop an exhaustive inventory of all conceivable solutions ahead of time." This is not so for wicked opportunities, given that, in the context of the marketplace, their flexible and open organizational structure, and the inventory of opportunities they can address need not be exhaustive, nor should the organization wish to devote resources to develop such a list. Instead, the open-ended 
nature of marketplaces welcomes market manager and stakeholder creativity as they balance opportunity-seeking and problem-solving in their daily lives.

\section{Problems or Opportunities? Questions of Time, Place, and Scale}

Consider this: When we read magazines and newspapers or browse media feeds, why do we see photos of outdoor markets as illustrations of many types of subject matter? Flourishing communities, prosperous local economies, thriving cities, civil politics, robust public life, and more? The reason is twofold. On one hand, each of these subjects is difficult to exemplify comprehensively, composed as they are of so many facets; on the other hand, photos present moments in multiple narrative threads simultaneously, conjuring the "thousand words" it would take to convey the accumulated experiences that make for attractive outcomes. Indeed, our minds impose topics and impress stories on each visual object we discern. No matter how evocative the image, there remains an ambiguity and curiosity about the stories making up each discernable thread. At one and the same time the observer recognizes themselves in the photo's activities and recognizes that those activities are scaffolded with much that is unseen and ramifying, recognizably, but in ways both unexpected and unpredictable.

This sounds like a wicked problem. One's senses are assailed navigating the busy marketplace, some markets being so busy they can make one uncomfortable. For us, they are undefinable, indecipherable, and possess unpredictable elements, so we see many characteristics of the wicked problem. How do we distinguish problem from opportunity, wicked as they both can be? I proceed by focusing on contrasts in narrative time and place, and scale.

Rittel and Webber were writing at a time of grand narratives. The intellectual history of the time was dominated by ebb-and-flow conceptualizations of society. Rittel and Webber assessed a time when grand narratives held the highest scientific status and technocratic solutions abounded. For instance, Parsons reigned supreme in sociology, Lipmann and Dewey debated the nature of the public in philosophy and political science, and the institutionalism of Commons and the interest in Smith's Theory of Moral Sentiments gave way to the Keynes macroeconomy and Smith's "invisible hand." Though the grand narrative reigned, many social scientists preserved and developed lines of thinking which eschewed the abstract to instead comprehend people's understanding of and connection to their organizational and relational circumstances. I think of C. W. Mills and Everett Hughes as being among them, importantly also G. H. Mead, and the inheritors of Commons. These scholars were holding a place, waiting for Becker to complement his jazz piano with his sociology, for Leaf to do his ethnography of the Panjab, Falk-Moore her ethnography of Mount Kilimanjaro, and for Siegfried to remind us of the role women played in the intellectual history of pragmatism. In short, other scholars would reinvigorate schools of thought united in their concern for showing how connecting mind to interaction to social organization made possible not just understanding society but supporting its operation [19-21].

In that section of their article, Goal Formation, Rittel and Webber remind us there is no such thing as the "mass society" predicted by some social scientists or a "melting pot" accommodating all, which other social scientists described. Indeed, they eschew questions of "what do the systems do" and urge us to replace them with "what should these systems do?" [7] (p. 157). The wicked problem they go on to identify emerged with respect to the dominant way of thinking about society in terms of grand narratives and technocratic solutions. Political-organizational thinking associated with the nation as a whole treated America as homogeneous by leveling diversity and proposing unrealizable objectives and technocratic strategies (see their brief treatment of Eisenhower's national goals, etc., at p. 157). Thus, Rittel and Webber implicitly point out the need for appropriately scaled understandings of society.

The grand narrative implies a large scale, and scale is the second vitally important difference we consider in our moment. If we take seriously the notion of e pluribus unum, then our national narratives should anchor to principles that help establish goals 
appropriate to the problem and circumstance. Rittel and Webber's view of the wicked problem feels scale independent, but remember, it focuses on the difficulties of large bureaucracies in tackling circumstances that have no technical solution, are absent of shared values, etc. By describing the reality of pluralism and the absence of a shared culture, they assume the absence of shareable goals or organizing principles. They write: "Surely a unitary conception of a unitary 'public welfare' is an anachronistic one." [7] (p. 168). Here, they cast away a useful principle of governance and social organization, regarding it as an unachievable goal.

However, Rittel and Webber need not have made the leap. They did so because they conflated constitutional principles with the actual practices of people and organizations in the name of those principles. When they point out the difficulties in problem definition that hobble our thinking, from their perspective it follows that such principles are inarticulable, impractical, or not implementable. They recognize the theoretical dilemma and summarize in their conclusion: "We are also suggesting that none of these tactics will answer the difficult questions attached to the sorts of wicked problems planners must deal with ....We are inclined to think that these theoretic dilemmas may be the most wicked conditions that confront us." [7] (p. 169). This is surely the case when the dominant theories reflect grand narrative structures that homogenize experiences and cannot distinguish between people's practices as understood in context. Instead, theory must locate practices in distinct institutions, in particular circumstances and instances, and unfolding over time, based on the principles of public welfare that help organize those practices. We would not want to sum up the local narratives in some abstract, magical way, but instead recognize them for what they are, the mundanity of people practicing their everyday lives. What is magical is our direct experience of daily marketplace mundanity. This mundane place is part and parcel of many interwoven processes, supporting many interdependent goals, and painting a picture of community composed of interactions between people as they enact different, meaningful ideas.

\section{Wicked Opportunities in Food Supply Chains, Including Markets}

In this essay I can only outline important developments in the food system that represent opportunities for wicked thinking. Consider a large-scale problem: that of food supply chains and distribution networks. We recognize these were designed with efficiency in mind and were successful in the time of 'tame' problems, where technical solutions, e.g., linear programming, were useful in trip planning and coordinating delivery of processed products, even around the world. However, here, I want to connect wicked opportunity thinking to food through technological possibilities, possibilities that imply substantial commitments in human resources, and with substantial potential for deep, inclusive, and long-lasting benefits.

Bringing technology to the direct market food economy found in farmers markets, community supported agriculture, and the like, has required an investment in organizations and practices (social and technological) dedicated to that community. This would include Extension, urban planners, food security organizations and others. Doing so will benefit marketplace practitioners. For instance, the ecosystem services metrics associated with Farm 2 Facts will provide consumers and other stakeholders with knowledge about the noneconomic benefits of small farmers, such as habitat preservation and carbon sequestration.

Of course, there will be many components that managers of direct market food enterprises might use to support consumers, such as electronic benefits transfers found at some farmers markets, market management software such as marketwurks.com, and market data collection software such as Farm2Facts.org and integrations of these, with geospatial data and services to provide rich decision-making resources to stakeholders in the community. Certainly, many members of this community are in the community because they seek to be off the grid or otherwise have privacy concerns. It will be the case that not all participants in direct market agriculture will participate in technological solutions or decision support tools. Nonetheless, many users will want to leverage the 
opportunities provided by such tools, and market managers, scholars, and others need increased investment in the sector, represented by the USDA Agricultural Marketing Service and complementing the work of the Food and Nutrition Service [22].

We can enhance food system traceability, transparency, and trust, even in the direct market sector where "Know your Farmer" leads the way. We can also enhance the resilience of communities through technology that organizational stakeholders in the world of risk management and disaster preparation can utilize to help mitigate the risk to communities experiencing food supply disruptions induced by climate change. An investment in technology for direct market agriculture is vitally important to local community economic development. Such an investment, if integrated with precision agriculture, directed to benefit future generations, and incorporating supportive stakeholders, will produce substantial direct and corollary benefits across the food system, with respect to communities rural and urban across the U.S., and the world, and at the same time help prepare future generations for further technological innovations.

Technology is no panacea; indeed, discomfort and dislocations follow from technological change, and further, such changes are unevenly adopted, particularly in sectors of the agricultural community that for a variety of reasons eschew technology. However, I am not suggesting that these technologies in and of themselves are wicked opportunities (though they might be, and they could be wicked problems). Instead, they are tools, complex ones perhaps, but tools nevertheless, that are utilized by the more important contrivance of human organization, which is the principal mode for transforming terrible troubles into wicked opportunities.

\section{Conclusions}

A robust society is like a healthy ecology, constantly being disrupted by differentiations that alter habitual interactions, cause reactions, and create novel interactions in new niches. COVID-19 puts this principle in action-as we have seen, mutation is endemic and permits fitness to host environments. Many aspects of our social life can be framed as wicked opportunities. For instance, in the U.S., stimulus spending can trigger new approaches to economic life by fostering wicked opportunity thinking. Recent history reminds us that farmers markets reemerged 50 years ago to swiftly repopulate our retail food environment, exploiting emergent interests in the ecology, individual health, and flavors that consumers felt were abandoned by commodity food production. Analogous thinking is possible in other domains.

Still, as one would suspect, we have much to learn about marketplaces and how they are incorporated into each time and place. First, in the nation-state context, we have good research about individual markets in particular places, but we lack knowledge of market organizations and their role in regional geographies. We need longitudinal data to help us disentangle the reciprocal relationships between markets and other elements of their political-economic context. Second, we must remember how important trade has been historically and how responsive it has been to demographic difference. Our work must comprehend demographic difference at markets and how such differences become opportunities of various kinds, including opportunities for self-determination, for inclusive economic spaces, and for reconstructing trade in the service of society, instead of the other way around. Third, we need research on supra-market relationships to other important social goals, such as health surveillance, community resilience, and responsiveness to external shocks, whether they are economic, health, or ecological.

Furthermore, we need to locate the market in the ongoing formation of socio-political identities. We need to see wicked opportunities as systems of ideas and interaction unfolding in processes, that may be difficult to define, yet are tangible and immediate. From that perspective, "wicked opportunities" offer us a view of democratic processes as interaction and practice, with underlying ethics in the service of those purposes and practices. In short, we must remember that in different historical epochs markets served many func- 
tions and today, they go underutilized. Which means, of course, that the marketplace is a wicked opportunity.

Funding: This research received no external funding.

Institutional Review Board Statement: Not applicable.

Informed Consent Statement: Not applicable.

Data Availability Statement: Not applicable.

Acknowledgments: I am grateful to anonymous reviewers, as well as colleagues, including Beth Plale, Simon Weffer, Marie Theresa Hernandez, Rodolfo Rosales, Arden He, Brian Wiedenfeld, Tracy Harvey, and Catie DeMets. Their useful comments and critiques improved this work. Thanks also to Dan Vimont for his invitation to present “Wicked Problems? Wicked Opportunities! Direct and Indirect Responses to Climate Change and Ensuing Natural Hazards" to the UW-Madison program, Climate, People, and Environment, in 2014. I look forward to developing the ideas here with him, and others.

Conflicts of Interest: Alfonso Morales was a co-founder of Farm 2 Facts as described in Ledesma et. al.

\section{References}

1. Morales, A. Peddling Policy: Street Vending in Historical and Contemporary Context. Int. J. Sociol. Soc. Policy 2000, 20 , 76-99. [CrossRef]

2. Morales, A. Public Markets as Community Development Tools. J. Plan. Ed. Res. 2009, 28, 426-440. [CrossRef]

3. Ledesma, E.; Giusti, C. Why Latino Vendor Markets Matter. J. Am. Plan. Assoc. 2021. [CrossRef]

4. Weber, M. From Max Weber: Essays in Sociology; Gerth, H., Mills, C.W., Eds.; Oxford University Press: New York, NY, USA, 1946.

5. Weber, M. Economy and Society; Roth, G., Ed.; Bedminster Press: New York, NY, USA, 1968.

6. Morales, A. Public Markets: Prospects for Social, Economic, and Political Development. J. Plan. Lit. 2011, 26, 3-17. [CrossRef]

7. Rittel, H.; Webber, M. Dilemmas in a general theory of planning. Policy Sci. 1973, 4, 155-169. [CrossRef]

8. Morales, A.; García, A.M.; Timmermans, W.; Crecente, R.; Woudstra, A. Scenario Planning for the Food System: A Plan for Lugo, Spain. Interplan 2013. Available online: https://localfoodeconomics.com/wp-content/uploads/2018/02/Morales-et-al-2013 -food-planning-in-Spain.pdf (accessed on 26 May 2021).

9. Hopkins, L.; Zapata, M. Engaging the Future: Forecasts, Scenarios, Plans, and Projects; Lincoln Institute of Land Policy: Cambridge, MA, USA, 2007.

10. Morales, A.; Balkin, S.; Persky, J. The Value of Benefits of a Public Street Market: The Case of Maxwell Street. Econ. Dev. Q. 1995, 9, 304-320. [CrossRef]

11. Sherry, J.F.J. The Sociocultural Analysis of a Midwestern American Flea Market. J. Cons. Res. 1990, 17, 1-18. [CrossRef]

12. Morales, A. Growing Food AND Justice: Dismantling Racism through Sustainable Food Systems. In Cultivating Food Justice: Race, Class and Sustainability; Alkon, A., Agyeman, J., Eds.; MIT University Press: Cambridge, MA, USA, 2011.

13. Considerations for Outdoor Farmers Markets. Available online: https://www.cdc.gov/coronavirus/2019-ncov/community/ outdoor-farmers-markets.html (accessed on 21 May 2021).

14. Byker, C.; Shanks, J.; Misyak, S.; Serrano, E. Characterizing Farmers' Market Shoppers: A Literature Review. J. Hunger. Environ. Nutr. 2012, 7, 38-52. [CrossRef]

15. Morales, A. Differentiate or Die: Reconstructing market(place) economies. Agric. Hum. Values 2020, 37, 545-546. [CrossRef] [PubMed]

16. Pisani, M.J.; Morales, A. Informality and Latino-Owned Businesses: A National Portrait of Unregistered Latino-Owned Businesses. Soc. Sci. Q. 2020, 101, 588-603. [CrossRef]

17. Clark, M.A.; Domingo, N.G.G.; Colgan, K.; Thakrar, S.K.; Tilman, D.; Lynch, J.; Azevedo, I.L.; Hill, J.D. Global food system emissions could preclude achieving the $1.5^{\circ}$ and $2{ }^{\circ} \mathrm{C}$ climate change targets. Science 2020, 370, 705. [CrossRef] [PubMed]

18. Horwath, W.R.; Kuzyakov, Y. The Potential for Soils to Mitigate Climate Change Through Carbon Sequestration. Dev. Soil Sci. 2018, 35, 61-92.

19. Albrecht, C.; Smithers, J. Reconnecting through local food initiatives? Purpose, practice and conceptions of 'value'. Agric. Hum. Values 2018, 35, 67-81. [CrossRef]

20. Morales, A. Pragmatism's Mundanity: Epistemic Foundations for a Practicing Socio-legal Science. In Review of Realistic Socio-Legal Theory; Tamanaha, B., Ed.; Oxford University Press: Oxford, UK, 1998; Volume 32, pp. 493-514.

21. Morales, A. Planning and the Self-Organization of Marketplaces. J. Plan. Ed. Res. 2010, 30, 182-197. [CrossRef]

22. Wilson, M.; Witzling, L.; Shaw, B.; Morales, A. Contextualizing Farmers' Market Needs: Assessing the Impact of Community Type on Market Management. J. Food Distrib. Res. 2018, 49, 1-18. 